\title{
РЕАЛЬНІ ГОРИЗОНТИ ПЕРСОНАЛІЗОВАНОЇ МЕДИЦИНИ. СТРАТЕГІЯ ТА ВАРІАНТИ РОЗВИТКУ
}

\author{
О. П. Мінцер, В. В. Вишневський ${ }^{1}$ \\ Національна медична академія післядипломної освіти імені П. Л. Шупика \\ ${ }^{1}$ /нститут проблем математичних машин та систем НАН України
}

\begin{abstract}
Розглянуто найближчі та віддалені перспективи персоналізованої медицини. Підкреслюється, що найбільші результати слід очікувати на тепер від пацієнт-орієнтованого підходу в діагностиці, прогнозуванні та виборі лікувального впливу, в моніторингу станів та оцінюванні ризиків. Особлива увага приділена можливості розгляду розвитку патології як хвильового процесу з трендами, що підлягають визначенню (обчисленню). Подано узагальнену концепцію представлення та кількісного аналізу трендів показників.
\end{abstract}

Ключові слова: персоналізована медицина, мобільна медицина, пацієнт-орієнтована медицина, трансдисциплінарність, геномно-протеомна діагностика, геномний паспорт людини, предиктивна медицина, індивідуальне здоров'я, характеристичні симптоми, сталі стани в розвитку патології.

\section{РЕАЛЬНЫЕ ГОРИЗОНТЫ ПЕРСОНАЛИЗИРОВАННОЙ МЕДИЦИНЫ. СТРАТЕГИИ И ВАРИАНТЫ РАЗВИТИЯ}

\author{
О. П. Минцер, В. В. Вишневский \\ Национальная медицинская академия последипломного образования имени П. Л. Шупика \\ ${ }^{1}$ Институт проблем математических машин и систем НАН Украины

\begin{abstract}
Рассмотрены ближайшие и отдаленные перспективы персонализированной медицины. Подчеркивается, что наибольшие результаты можно ожидать в настоящее время от пациент-ориентированного подхода в диагностике, прогнозировании и выборе лечебного воздействия, в мониторинге состояний и оценке рисков. Особое внимание уделено возможности рассмотрения развития патологии как волнового процесса с трендами, которые возможно определить (вычислить). Рассмотрена обобщенная концепция представления и количественного анализа трендов показателей.
\end{abstract}

Ключевые слова: персонализированная медицина, мобильная медицина, пациент-ориентированная медицина, трансдисциплинарность, геномно-протеомная диагностика, геномный паспорт человека, предиктивная медицина, индивидуальное здоровье, характеристические симптомы, устойчивые состояния в развитии патологии.

\section{THE REAL HORIZONS OF PERSONALIZED MEDICINE. STRATEGY AND DEVELOPMENT OPTIONS}

\author{
O. P. Mintser, V. V. Vyshnevskyy ${ }^{1}$ \\ Shupyk National Medical Academy of Postgraduate Education \\ ${ }^{1}$ Institute of Mathematical Machines and Systems Problems, NAS of Ukraine
}

\begin{abstract}
It's discussed the immediate and long-term prospects of personalized medicine. It is emphasized that the greatest results can be expected at the present time from a patient-oriented approach in the diagnosis, prognosis and the choice of the treatment modality, state monitoring and risk assessment. Particular attention has been paid to the possibility of considering the development of pathology as a wave process with trends that are possible to determine (calculate). It's proposed a generalized representation of the concept and quantitative analysis of symptoms trends.
\end{abstract}

Key words: personalized medicine, medicine mobile, patient-oriented medicine, transdisciplinarity, genomic and proteomic diagnostics, genomic passport rights, predictive medicine, individual health, characteristic symptoms, stable states in the disease development. 
Вступ. Численні критики розвитку галузі охорони здоров'я вважають, що остання знаходиться в критичній ситуації через дорожнечу енергоємність, неефективність та зосередження переважно на використанні універсальних методів лікування. У ряді випадків використовується обмежена кількість лікарських засобів «на всі випадки життя». Ефективність та безпечність лікарських засобів не гарантується. I далеко не завжди досягається запланований результат [9].

Лише останнім часом з'явився новий напрям сучасної медицини, який набув широкий резонанс та з яким пов'язують радикальні зміни в медицині. Він отримав назву «персоналізована (індивідуалізована, персоніфікована) медицина» $[5,7,9,12$, 15]. Незважаючи на відмінності в численних трактуваннях, можна виділити загальну концепцію, яка полягає в тому, що персоналізована медицина включає адаптацію діагностики та лікування до індивідуальних особливостей пацієнта.

При цьому під наближенням медичних процедур розуміється досить широкий діапазон від виділення субпопуляції до конкретного індивіда 3 включенням факторів схильності до розвитку певного захворювання або відповіді на конкретне лікування [3, 4, 10-13, 16].

Відповідно в одному вкрай важливому випадку мається на увазі забезпечення цільової діагностики і лікування, причому діагностика здійснюється на базі геномно-протеомної, метаболомної і транскриптомної інформації, а лікування - 3 використанням індивідуально орієнтованих впливів, зокрема лікарської і клітинної терапії відповідно до вихідних результатів дослідження генетичного профілю хворого [4, 6, 13, 16, 17].

У підсумку, для персоналізованої медицини особливий інтерес представляє генетичний паспорт здоров'я, який містить інформацію про особливості структури ДНК, індивідуальну схильність до ряду спадкових захворювань. Він же визначає рекомендації для пацієнта і його лікуючого лікаря щодо профілактики захворювань за умов підвищеного ризику їх розвитку. За допомогою процедур молекулярної діагностики, зокрема доклінічної і пренатальної, можна виявити понад десяток тисяч форм захворювань, які мають генетичне підгрунтя.

Основною перешкодою поширення персоніфікованої медицини вважалася її висока вартість. Однак якщо ще вісім-десять років тому секвенування генома коштувало сотні тисяч доларів, то сьогодні ця сума не перевищує однієї тисячі доларів. Не виключено, що вже через кілька років подібні процедури перетворяться в рутинні, тим більше що сьогодні в світі налічується тисячі майданчиків для геномних досліджень (поки, переважно, вони зосереджені на території США).

Персоналізована медицина, по суті, є інтегративним трансдисциплінарним напрямом, що об'єднує новітні біотехнологічні підходи в аналізі патогенезу захворювань та, особливо, їх молекулярній діагностиці і терапії. А також такі напрями медико-біологічних досліджень, як фармакогеноміка, фармакогенетика, метаболоміка, фармакопротеоміка, фармакометаболоміка, фармакоцитоміка [2, $8,17]$. Істотний внесок у розвиток персоналізованої медицини вносять і нанобіотехнології. їхній вплив обумовлений використанням інноваційних методик для лікувально-діагностичних цілей [10].

В іншому крайньому випадку (який, на нашу думку, є найбільш перспективним на сьогодні) для діагностики та лікування хворого забезпечується складання багатофакторної бази даних на кожного пацієнта, що забезпечує облік його біологічних i психосоціальних особливостей. Загальна картина складається 3 безлічі деталей - результатів аналізу роботи різних систем організму (в необхідних випадках - на молекулярному рівні), наявності спадкових патологій i, навіть, опису особливостей стосунків у сім'ї. У підсумку лікар інтегрує поведінкові, метаболічні, конституціональні, екологічні чинники з фундаментальними методами диференціальної діагностики хвороб.

Подібний підхід отримав назву «пацієнт-орієнтована діагностика і лікування» [9]. Особливістю такого підходу повинні стати не симптоми, навіть характеристичні, кількість яких становить тисячі. Важливості набувають особливості динаміки показників (при навантаженні, тимчасової та при поверненні до вихідного стану після лікування), які є унікальними для кожного пацієнта. На нашу думку, аналіз трендів на сьогодні є єдиним варіантом персоналізації підходу до лікування пацієнтів.

Слід зазначити, що до концепції персоніфікованої медицини можна віднести й роботи української школи валеології, предметом якої є індивідуальне здоров'я. Передусім, це роботи проф. Г. Апанасенка та його школи [1]. Головною ідеєю валеології $\epsilon$ вивчення не хвороби або патологічного стану, а навпаки - рівня здоров'я. При цьому валеологія має методи визначення такого рівня безпечного здоров'я, який є захищеним для будь-яких неінфекційних хвороб. Відповідно до валеологічних 
поглядів, як мінімум, можна встановити та виділити три періоди в житті людини, які визначають погляди на функціональність приладів для оцінки рівня та стану здоров'я: період здоров'я, період передзахворювання або ранньої діагностики та період лікування. При цьому сучасне діагностичне обладнання відповідає лише періоду лікування, оскільки саме для цього періоду актуальна диференційна діагностика хвороби. Для інших періодів більш актуальним $є$, на погляд валеологів, визначення не захворювання, а рівня здоров'я.

Незалежно від концептуального уявлення персоналізованої медицини, сьогодні цей напрям являє собою область медичних знань, що бурхливо розвивається. Оцінка Бостонської консалтингової групи свідчить, що до 2020 року темпи зростання персоналізованої медицини становитимуть 37 \% щорічно [2, 14].

Мета роботи: надати уявлення про найближчі та віддалені перспективи розвитку персоналізованої медицини.

Результати та їх обговорення. Постулюється, що в індивідуалізації діагностики та лікування пацієнтів основою $є$ використання такої інформації про стан хворого, яка ідентифікує та визначає як особливості моніторингу його стану, так і принципи обраного лікування. По суті, йдеться про використання методів спрямованого пацієнторієнтованого лікувально-діагностичного впливу на основі врахування впливів середовища, генетичних та регіональних чинників [9]. Важливо відзначити, що подібні технології, які з'явилися в розпорядженні медиків, дозволяють виділити індивідуальні особливості кожного пацієнта. Реальним стає також генетичний прогноз ризиків як на рівні цілого етносу, так і на рівні сім'ї і конкретного індивіда.

Після отримання первинної інформації можливо застосування концепції персоніфікованої, або предикативної (попереджувальної) медицини, яка здатна істотно підвищити якість лікування. Одним 3 нових факторів подібної стратегії $є$ виявлення, оцінка, моніторинг та визначення ступеня впливу ризиків погіршення стану. Обгрунтування ризиків проводиться на базі вже згаданих характеристичних симптомів, які складаються не з загальної кількості всіх показників (їх тисячі!), а з особливостей динаміки показників, що є унікальними для кожного пацієнта. Виділяють три групи: динаміка показників при адаптації до навантаження, динаміка показників під час стійкого навантаження i, нарешті, динаміка повернення до вихідного стану після навантаження. При такому підході можливо враховувати і знання, накопичені вітчизняною школою валеології, комбінуючи підходи для оцінки рівня здоров'я та диференціальної діагностики.

Зрозуміло, можливо розглядати і динаміку при фармацевтичному навантаженні або лікувальних процедурах. У рамках запропонованого підходу вважаємо, що аналіз трендів - один із нечисленних варіантів персоналізованого підходу до лікування пацієнтів на сьогодні. Однак дотепер не розроблені коректні методики оцінювання динаміки факторів ризику в часі, придатні для клінічної практики. В певній мірі таке положення обумовлено великою кількістю факторів ризику, що становлять сотні, навіть якщо враховувати тільки широко відомі та поодинокі етапи дослідження.

Одним із можливих і методично найбільш пророблених шляхів вирішення даної проблеми $\epsilon$ апроксимація ряду значень показника х (xi, $x 2, \ldots$, $x$ ) функцією $F(x)$ і подальша класифікація у безлічі $\{F(x)\}$, що є функціональними залежностями зміни безлічі показників. При цьому виникає цілий ряд труднощів, насамперед, у питанні про інтерпретацію поняття «динаміка фактора ризику». Можна надати кілька шляхів формалізації динамічних змін деякого фактора (х). Більш перспективними представляються нам відносні їх зміни. Подібний підхід до оцінки змін припускає вибір деякої точки чи множини, відносно центру якої проводиться вимір значень показника.

Вважаємо за необхідне зробити ще одне важливе зауваження. На досить великому проміжку часу, коли з'являється донозологічна патологія (чи явна патологія!), завжди є можливість повернення до стану повного здоров'я чи стійкого стану, що дозволяє пацієнту бути збалансованим з навколишнім середовищем (інакше навіщо тоді існує медицина і навіщо потрібні власні зусилля з повернення до здоров'я?!). Іншими словами, тріада термінів (здоров'я - донозологічна патологія - хвороба) на тимчасовому графіку відображається як хвильовий процес 3 трендами, які можна визначити (а іноді й обчислити). Звичайно, не можна забувати і про те, що в організмі протікає багато процесів, кожен 3 яких може бути інтерпретований як донозологічний стан або хвороба.

Висновки. 1. Зауважено на необхідність більшого поширення пацієнт-орієнтованого підходу в діагностиці, прогнозуванні та лікуванні, моніторингу станів пацієнтів і оцінюванні ризиків. 
2. Постулюється, що тріаду процесів (здоров'я - до нозологічна патологія - хвороба) на темпоральній осі можна відобразити як хвильовий процес із трендами, які можна визначити (обчислити).

\section{Література.}

1. Апанасенко Г. Биологическая деградация НОМО SAPIENS: пути противодействия. Основы. Концепции. Методы / Г. Апанасенко, В. Гаврилюк - Saarbrücken : Palmarium Academic Publishing, 2014. - 96 c.

2. Доклад о состоянии здравоохранения в Европе 2015 г. Целевые ориентиры и более широкая перспектива - новые рубежи в работе с фактическими даннями [Электронный ресурс] / Европейское региональное бюро BО3. - 2015. - Режим доступу: http://www.euro. who.int/ru/data-and-evidence/european-health-report 2015.

3. Персонализированная медицина: современное состояние и перспективы / И. И. Дедов, А. Н. Тюльпаков, В. П. Чехонин [и др.] // Вестник РАМН. - 2012. - № 12 . - C. 4-10.

4. Berg J. S. Deploying whole genome sequencing in clinical practice and public health: Meeting the challenge one bin at a time / J. S. Berg, M. J. Khouiy, J. P. Evans // Genetics in Medicine. - 2011. - Vol. 13, No. 6. - P. 499-504.

5. Chan I. S. Personalized medicine: progress and promise / I. S. Chan, G. S. Ginsburg//Annu. Rev. Genomics Hum. Genet. - 2011. - Vol. 12. - P. 217-244.

6. Garrison Jr. L. P. The economics of personalized medicine: a model of incentives for value creation and capture / L. P. Garrison Jr., M. J. Austin// Drug Information Journal. - 2007. - Vol. 41. - P. 501-509.

7. Hamburg M. A. The path to personalized medicine / M. A. Hamburg, F. S. Collins // N. Engl. J. Med. - 2010. Vol. 363, No. 4. - P. 301-304.

8. Hoggatt J. Personalized medicine trends in molecular diagnostics: exponential growth expected in the next ten years / J. Hoggatt // Mol. Diagn. Ther. - 2011. - Vol. 15, No. 1. - P. 53-55.

9. Jain K. K. From molecular diagnostics to personalized medicine / K. K. Jain // Exp. Rev. Mol. Diagn. - 2002. - Vol. 2, No. 4.-P. 299-301.

10. Jain K. K. Nanobiotechnology and personalized medicine / K. K. Jain // Prog. Mol. Biol. Transl. Sei. - 2011. - Vol. 104. - P. 325-354.

11. Nebert D. W. Personalize medicine: temper expectations / D. W. Nebert, G. Zhang // Science. - 2012. - Vol. 337, No. 6097.-P. 910.

12. Nishiyama M. Personalized medicine and molecular targets of drugs / M. Nishiyama // Nihon Rinsho. - 2010. -Vol. 68, No. 10. - P. 1917-1922.

13. Mirnezami R. Preparing for precision medicine / R. Mirnezami, J. Nicholson, A. Darzi // N. Engl. J. Med. 2012. - Vol. 366, No. 6. - P. 489-491.

14. Molecular medicine: a path towards a personalized medicine / D. M. Miranda, M. Mamede, B. R. Souza [et al.] // Rev. Bras. Psiquiatr. - 2012. - Vol. 34, No. 1. - P. 82-91.
15. Pollack A. Drug companies pursue personalized medicine approach [Electronic resource] / A. Pollack // New York Times. - 2010. - (November 16). - Retrieved from https://prescriptions.blogs.nytimes.com/2010/11/16/ drug-companies-pursue-personalized-medicine-approach/. 16. ScudellariM. Genomics contest underscores challenges of personalized medicine / M. Scudellari // Nat. Med. 2012.-Vol. 18, No. 3,-P. 326.

17. Spear B. B. Clinical application of pharmacogenetics / B. B. Spear, M. Heath-Chiozzi, J. Huff // Trends Mol. Med. - 2001. - Vol. 7, No. 5. - P. 201-204.

\section{References.}

1. Apanasenko, G., Gavrilyuk, V. (2014). Biologicheskaya degradatsiya HOMO SAPIENS: puti protivodeistviya. Osnovy. Kontseptsii. Metody [The biological degradation of the Homo Sapiens: the path of resistance. Fundamentals. Concept. Methods]. Saarbrücken: Palmarium Academic Publishing. [In Russian].

2. The European health report 2015. Targets and beyond reaching new frontiers in evidence. (14.07.2015). Retrieved from http:/www.euro. who.int/ru/data-and-evidence/ european-health-report2015 [In Russian].

3. Dedov, I. I., Tyul'pakov, A. I., Chekhonin, V. P., Baklaushev, V. P., Archakov, A. I., Moshkovskii, S. A. (2012). Personalized medicine: state-of-the-art and prospects. Annals of the Russian academy of medical sciences, 67(12), 4-12. [In Russian]. doi:10.15690/vramn. v67i12.474.

4. Berg, J. S., Khoury, M. J. \& Evans, J. P. (2011). Deploying whole genome sequencing in clinical practice and public health: Meeting the challenge one bin at a time. Genetics in Medicine , 13(6), 499-504. doi: 10.1097/ GIM.0b013e318220aaba.

5. Chan, I. S. \& Ginsburg, G. S. (2011). Personalized medicine: progress and promise. Annu. Rev. Genomics Hum. Genet., 12, 217-244. doi: 10.1146/annurevgenom-082410-101446.

6. Garrison, Jr. L. P. \& Austin, M. J. (2007). The economics of personalized medicine: a model of incentives for value creation and capture. Drug Information Journal, 41, 501-509.

7. Hamburg, M. A. \& Collins, F. S. (2010). The path to personalized medicine. N. Engl. J. Med., 363(4), 301-304. doi: 10.1056/NEJMp1006304.

8. Hoggatt, J. (2011). Personalized medicine trends in molecular diagnostics: exponential growth expected in the next ten years. Mol. Diagn. Ther., 15(1), 53-55. doi: 10.2165/11534880-000000000-00000.

9. Jain, K. K. (2002). From molecular diagnostics to personalized medicine. Exp. Rev. Mol. Diagn., 2(4), 299-301.

10. Jain, K. K. (2011). Nanobiotechnology and personalized medicine. Prog. Mol. Biol. Transl. Sei., 104, 325-354. doi: 10.1016/B978-0-12-416020-0.00008-5. 
11. Nebert, D. W. \& Zhang, G. (2012). Personalized medicine: temper expectations. Science, 337(6097), 910. doi: 10.1126/science.337.6097.910-a.

12. Nishiyama, M. (2010). Personalized medicine and molecular targets of drugs. Nihon Rinsho, 68(10), 19171922.

13. Mirnezami, R., Nicholson, J. \& Darzi, A. (2012). Preparing for precision medicine. N. Engl. J. Med., 366(6), 489-491. doi: 10.1056/NEJMpl114866.

14. Miranda, D. M., Mamede, M., Souza, B. R., Almeida Barros, A. G., Magno, L. A., Alvim-Soares, Jr. A, ... Romano-Silva, M. A. (2012). Molecular medicine: a path towards a personalized medicine. Rev Bras. Psiquiatr., 34(1), 82-91.
15. Pollack, A. (2010, November 16). Drug companies pursue personalized medicine approach. New York Times. Retrieved from https://prescriptions.blogs.nytimes. com/2010/11/16/drug-companies-pursue-personalizedmedicine-approach/.

16. Scudellari, M. (2012). Genomics contest underscores challenges of personalized medicine. Nat. Med., 18(3), 326. doi: $10.1038 / \mathrm{nm} 0312-326$.

17. Spear, B. B., Heath-Chiozzi, M. \& Huff, J. (2001). Clinical application of pharmacogenetics. Trends Mol. Med., 7(5), 201-204. 